\section{Functional magnetic resonance imaging of the primary somatosensory cortex in piglets}

TO THE READERSHIP: An error appeared in the article by Duhaime et al. (Duhaime AC, Saykin AJ, McDonald BC, et al. Functional magnetic resonance imaging of the primary somatosensory cortex in piglets. J Neurosurg. 2006;104[4 Suppl]:259-264).

In the legend of Fig. 2, the time at which the springloaded indentor tip was fired was given as $400 \mathrm{msec}$. The correct timeframe is $4 \mathrm{msec}$. The corrected figure legend is shown below.

FIG. 2. Schematic representation of the cortical injury device (piglet scaled cortical impact model). The indentor tip diameter and indentation depth can be varied in animals of different ages such that these parameters increase in proportion to the increases in brain dimensions with growth. In this way, $1 \%$ of the total brain volume is displaced by the indentor over $4 \mathrm{msec}$, and strain to specific structures is held constant. Because the volume of indentation is scaled for growth, comparable brain regions are injured at each subject age.
The article has been corrected online as of May 29, 2020 .

Ann-Christine Duhaime, MD

Massachusetts General Hospital, Boston, MA

INCLUDE WHEN CITING

Published online May 29, 2020; DOI: 10.3171/2020.5.PEDS2015781a.

CAANS 2020, except where prohibited by US copyright law 